\title{
Pathologic Intimal Thickening
}

National Cancer Institute

\section{Source}

National Cancer Institute. Pathologic Intimal Thickening. NCI Thesaurus. Code C139156.

A term that refers to a vascular lesion characterized by an extracellular lipid pool with intimal smooth muscle cell loss typically adjacent to the medial wall in addition to varying degrees of macrophage infiltration near the lumen. (Arteriosclerosis, Thrombosis, and Vascular Biology. 2007; 27:986-989) 